\title{
Axillary Sentinel Lymph Node Biopsy for Breast Cancer and Melanoma Patients after Previous Axillary Surgery: A Systematic Review*
}

\author{
Maurice Matter ${ }^{1,2 \#}$, Sebastien Romy ${ }^{1,3}$, Ariane Boubaker ${ }^{4}$, Olivier Michielin ${ }^{2}$, Nicolas Demartines ${ }^{1}$ \\ ${ }^{1}$ Department of Visceral Surgery, Centre Hospitalier Universitaire Vaudois and University of Lausanne, Lausanne, Switzerland; \\ ${ }^{2}$ Department of Oncology, Melanoma Outpatient Clinic, Centre Hospitalier Universitaire Vaudois and University of Lausanne, \\ Lausanne, Switzerland; ${ }^{3}$ Hôpital de Payerne, Payerne, Switzerland; ${ }^{4}$ Department of Nuclear Medicine, Centre Hospitalier Universi- \\ taire Vaudois and University of Lausanne, Lausanne, Switzerland. \\ Email: \#maurice.matter@chuv.ch, sebastien.romy@hibroye.ch, ariane.boubaker@chuv.ch, olivier.michielin@chuv.ch, \\ demartines@chuv.ch
}

Received October $7^{\text {th }}, 2013$; revised October $30^{\text {th }}, 2013$; accepted November $7^{\text {th }}, 2013$

Copyright @ 2013 Maurice Matter et al. This is an open access article distributed under the Creative Commons Attribution License, which permits unrestricted use, distribution, and reproduction in any medium, provided the original work is properly cited.

\begin{abstract}
Objective: Sentinel lymph node biopsy (SLNB) is a validated staging technique for breast carcinoma. Some women are exposed to have a second SLNB due to breast cancer recurrence or a second neoplasia (breast or other). Due to modified anatomy, it has been claimed that previous axillary surgery represents a contra-indication to SLNB. Our objective was to analyse the literature to assess if a second SLNB is to be recommended or not. Methods: For the present study, we performed a review of all published data during the last 10 years on patients with previous axilla surgery and second SLNB. Results: Our analysis shows that second SLNB is feasible in 70\%. Extra-axillary SNs rate (31\%) was higher after radical lymph node dissection (ALND) (60\% - 84\%) than after SLNB alone (14\% - 65\%). Follow-up and complementary ALND following negative and positive second SLNB shows that it is a reliable procedure. Conclusion: The review of literature confirms that SLNB is feasible after previous axillary dissection. Triple technique for SN mapping is the best examination to highlight modified lymphatic anatomy and shows definitively where SLNB must be performed. Surgery may be more demanding as patients may have more frequently extra-axillary SN only, like internal mammary nodes. ALND can be avoided when second SLNB harvests negative SNs. These conclusions should however be taken with caution because of the heterogeneity of publications regarding SLNB and surgical technique.
\end{abstract}

Keywords: Breast Neoplasms; Melanoma; Sentinel Lymph Node Biopsy Dissection; Lymphatic Vessels; Surgery; Lymphatic Anatomy

\section{Background}

Breast cancer has an incidence of 126/100,000 and is the commonest neoplasm in women [1]. Risk for ipsilateral breast cancer recurrence in women with early-stage breast cancer and breast-conserving therapy is about $5 \%$ - 20\% [2]. On the other hand, melanoma has worldwide a growing incidence [3]. It is the fourth commonest neoplasm in women with an incidence of about 15/100,000. Distribution of melanoma location shows a high density

\footnotetext{
*Grant support: none.

Conflicts of interest statement: All authors disclose neither financial nor personal relationships with other people or organisations that could inappropriately influence their work.

${ }^{\#}$ Corresponding author.
}

on the back, shoulders and upper arms in women [4]. It is not definitively established if breast cancer incidence after melanoma is increased or not compared to incidence in the general population [5,6]. In a large registry of 1926 men with breast cancer, Satram-Hoang showed that relative risk for melanoma was 2.98 (relative risk of 52 for a second breast cancer) [7]. The study of Brower et al. showed that breast cancer was the commonest non skin second primary cancer in melanoma patients [8].

Due to these cancer incidences and some risks of recurrence, it is likely that women could be exposed to two sentinel lymph node biopsies (SLNB) or further surgery following radical axillary lymph node dissection (ALND). It has been initially claimed that previous axillary sur- 
gery would represent a contra-indication to SLNB in breast cancer patients due to the modification of lymphatic anatomy [9]. Subsequent observations and case studies have shown that 2 succeeding SLNB procedures for recurrent ipsilateral breast cancer were feasible [10].

Our tertiary academic centre includes a melanoma clinic run by medical and surgical oncologists and an accredited breast cancer centre. After facing patients with melanoma and a past medical history of SLNB for breast cancer, we decided to investigate this rare condition (3 out of 750 melanoma patients in our series). The purpose of our present study was to systematically review the literature in order to determine to what extent SLNB or ALND may alter lymphatic drainage and if a second SLNB could be considered reliable in this particular oncological setting.

\section{Materials and Methods}

A web search (Ovid Medline ${ }^{\circledR}$ ) was conducted over the last 10 years with following medical subject headings: sentinel lymph node biopsy, breast neoplasms, melanoma, second (title word), lymphatic anatomy and axilla. Following identification of publications of interest, this search was completed by Medline tools using "similar references" or "citing references". Case reports (1case) were discarded and some of these have been previously collected by Palit et al. [10]. Following data have been extracted: first axillary dissection (SLNB or ALND), success rate for second SLNB, number of patients and detailed sites for extra-axillary SLNB, rates of metastatic SN (sentinel node) and length of follow-up when available. All these data are summarised in Table 1. Other data were reviewed such as: definition of SN and protocol for the SN anatomopathological examination.

\section{Results}

Our literature research totalizes 523 patients in 17 different studies, which included between 2 and 117 patients each (Table 1) [9,11-26]. Overall SN was succesfully detected in 365/523 patients (70\%). Extraaxillary SLNB was encountered in 114/365 patients (31\%). This figure was quite variable throughout studies as all extraaxillary SN were not systematically searched for in all studies (especially internal mammary) despite the fact that there was a significant number of metastatic extraaxillary SNs. Extra-axillary locations included internal mammary, intramammary, interpectoral, parasternal, infraclavicular and cervical in. All these location have already been observed in primary SLNB for breast cancer [27]. Keeping in mind that SNs were not all removed, we can acknowledge 46 and 13 patients with axillary and non-axillary metastatic SNs respectively. Clear definition for SN was scarce, triple technique for SLNB was not always the rule: blue dye was not systematically used in some series. Complete SNs analysis with H.-E. and immunohistochemistry were performed in all but three studies [14,19,22]. A follow-up was available in half of the studies. No axillary recurrence was observed within a follow-up period ranging from 15 to 46 months.

\section{Discussion}

Our literature analysis shows data heterogeneity and lack of standardization of the various strategies. Despite this, our review suggests that SLNB after previous radical lymph node dissection in the same region is surgically feasible and seems oncologically to be reliable regarding the evaluation of potential lymphatic spreading of tumour cells. Lymphoscintigraphy should be regarded as the best examination tool for highlighting lymphatic anatomy and actual lymphatic drainage following a previous lymphatic dissection in the same regional lymphatic network. Lymphoscintigraphy shows definitively basin(s) where a SLNB must be performed, especially for trunk melanoma, where drainage is frequently unpredictable [28].

The 17 reviewed publications (Table 1), have to be compared with caution because of several limitations: 1) heterogeneity of series due to different kind of initial breast surgery (benign and malignant disease with past SLNB, ALND or no axilla surgery), 2) blue dye injection was not systematically performed, and different injection technique (peritumoral, intratumoral, subcutaneously) were used, 3) no systematic ALND performed in case of SLNB failure, 4) variability of nodes detection rate during lymphoscintigraphy, 5) number of SNs retrieved and number of patients, 6) lack of follow-up in order to confirm oncological value of second SLNB, among others.

A negative SLNB in breast cancer exposes to $0.3 \%$ axillary recurrence only, within a median delay of 20 months (range 4 - 63) [29]. So the follow-up reported in table 1 (range 15 - 46) could be an element for assessing that false negative results after second SLNB were controlled.

ALND, which was a common procedure in patients with breast cancer in the past, is now replaced by sentinel lymph node dissection as a validated staging procedure. It is generally accepted that a micrometastatic disease in sentinel nodes does not oblige to perform ALND in patients with breast cancer, while it is still a debated matter in melanoma patients. SLNB following previous breast and axillary surgery is another matter of debate. The number of metastatic lymph nodes is in parallel with the mean number of lymph nodes retrieved during a radical lymph node dissection. This mean number can be con- 
Table 1. Review of literature for second SLNB after previous SLNB and/or ALND.

\begin{tabular}{|c|c|c|c|c|c|c|c|c|c|c|}
\hline $\begin{array}{l}\text { Year, author } \\
\text { (reference) }\end{array}$ & $\begin{array}{c}\mathrm{N} \text { (first } \\
\text { axillary } \\
\text { surgery): } \\
\text { (SLNB/ } \\
\text { ALND) }\end{array}$ & $\begin{array}{l}\mathrm{N} \text { success } \\
\text { for second } \\
\text { SLNB }\end{array}$ & $\begin{array}{l}\text { Success } \\
\text { rate } \%\end{array}$ & $\begin{array}{l}\text { Patients } \\
\text { with } \\
\text { Extra } \\
\text { axillary } \\
\text { SLNB }^{\text {a }}\end{array}$ & IM & $\begin{array}{c}\text { Axillary } \\
\text { (i: ipsilateral/ } \\
\text { c: contralateral) }\end{array}$ & $\begin{array}{l}\text { Supraclavicular } \\
\text { (i: ipsilateral/ } \\
\text { c: contralateral) }\end{array}$ & $\begin{array}{l}\text { Other } \\
\text { Extra } \\
\text { axillary }\end{array}$ & $\begin{array}{c}\text { Patients with } \\
\text { positive SN } \\
\text { Ax. + } \\
\text { extra-ax. }\end{array}$ & $\begin{array}{c}\text { Median } \\
\text { follow-up } \\
\text { (months)/ } \\
\text { Axillary } \\
\text { recurrence }\end{array}$ \\
\hline 2004, Sood [11] & $4(4 / 0)$ & 4 & 100 & 4 & 2 & $0 \mathrm{i} / 1 \mathrm{c}$ & - & $2^{\mathrm{b}}$ & $1+0$ & NA \\
\hline 2005, Dinan [12] & $16(2 / 14)$ & 11 & 69 & 7 & 1 & $4 \mathrm{i} / 3 \mathrm{c}$ & $2 \mathrm{i} / 1 \mathrm{c}$ & $\begin{array}{l}1^{\mathrm{b}} \\
1^{\mathrm{c}}\end{array}$ & 0 & NA \\
\hline 2005, Agarwal [13] & $2(0 / 2)$ & 2 & 100 & 2 & - & $1 \mathrm{i} / 2 \mathrm{c}$ & & & $0+1$ & 25 and $14 / 0$ \\
\hline 2006, Newman [14] & $10(1 / 7)$ & 9 & 90 & 7 & 3 & $2 \mathrm{i} / 7 \mathrm{c}$ & - & - & 0 & NA \\
\hline 2006, Roumen [15] & $12(2 / 10)$ & 10 & 83 & 7 & 3 & $6 \mathrm{i} / 4 \mathrm{c}$ & - & $2^{\mathrm{i}}$ & $3+2$ & $\begin{array}{c}24 / 0 \\
\text { (negative SN) }\end{array}$ \\
\hline 2006, Taback [16] & $15(11 / 9)$ & 11 & 73 & 5 & 2 & $5 i / 3 c$ & $1 \mathrm{i}$ & $2^{f}$ & $2+1$ & $41 / 0$ \\
\hline 2007, Port [9] & $117(54 / 63)^{d}$ & 64 & 55 & 19 & 11 & $52 \mathrm{i} / 5 \mathrm{c}$ & $1 \mathrm{i}$ & $\begin{array}{l}1^{\mathrm{e}} \\
3^{\mathrm{b}}\end{array}$ & $8+2$ & $26.4 / 0$ \\
\hline 2007, Intra [17] & $65(65 / 0)$ & 63 & 97 & 5 & 4 & 63i/0c & $1 \mathrm{i}$ & - & $6+1$ & $45.9 / 0$ \\
\hline 2007, Barone [18] & $19(7 / 12)$ & 16 & 84 & NA & & $16 \mathrm{i}$ & & & $2+0$ & $15 / 0$ \\
\hline 2008, Koizumi [19] & $31(3 / 16)^{\mathrm{h}}$ & 29 & 94 & 12 & 5 & $17 \mathrm{i} / 7 \mathrm{c}$ & - & - & $1+3$ & NA \\
\hline 2008, Schrenk [20] & $30(13 / 13)^{g}$ & 19 & 63 & 5 & 4 & $15 \mathrm{i} / 1 \mathrm{c}$ & - & $1^{\mathrm{f}}$ & $4+0$ & NA \\
\hline 2008, Cox [21] & $56(56 / 0)$ & 45 & 80 & 1 & 1 & $45 \mathrm{i} / 0 \mathrm{c}$ & - & - & $9+0$ & NA \\
\hline 2008, Axelsson [22] & $47(1 / 43)^{1}$ & $20 / 44$ & 45 & 7 & $3^{1}$ & $24 \mathrm{i} / 1 \mathrm{c}$ & $2 \mathrm{i}$ & $2^{i}$ & 7 & NA \\
\hline 2008, Karam [23] & $20(4 / 11)^{j}$ & 13 & 65 & 2 & 1 & $15 \mathrm{i} / 0 \mathrm{c}$ & $1 \mathrm{i}$ & - & $2+0$ & NA \\
\hline 2009, Tasevski [24] & $18(3 / 15)$ & 12 & 67 & 9 & 5 & $5 \mathrm{i} / 5 \mathrm{c}$ & - & - & $0+3$ & NA \\
\hline $\begin{array}{c}\text { 2010, Van } \\
\text { der Ploeg [25] }\end{array}$ & $\begin{array}{l}36 \text { SLNB }^{\mathrm{k}} \\
12 \text { ALND }^{\mathrm{k}}\end{array}$ & $\begin{array}{c}26 \\
6\end{array}$ & $\begin{array}{l}72 \\
50\end{array}$ & $\begin{array}{c}17 / 26^{\mathrm{a}} \\
5 / 6\end{array}$ & $\begin{array}{c}10 \\
2\end{array}$ & $\begin{array}{l}19 \mathrm{i} / 0 \mathrm{c} \\
3 \mathrm{i} / 4 \mathrm{c}\end{array}$ & $\begin{array}{l}- \\
-\end{array}$ & $\begin{array}{l}5^{e} 2^{f} \\
3^{b}\end{array}$ & $\begin{array}{l}?^{\mathrm{k}} \\
2\end{array}$ & $39 / 0^{k}$ \\
\hline 2010, Derkx [26] & $13(13 / 0)$ & 5 & 38 & NA & - & $5 i$ & - & - & $1+0$ & $13 / 0$ \\
\hline Overall & 523 & 365 & 70 & $114 / 365$ & & & & & $46+13$ & \\
\hline
\end{tabular}

SLNB: previous sentinel lymph node biopsy. ALND: previous axillary radical lymph node dissection. IM: internal mammary. Other extra-axillary SNs: bintramammary, 'cervical, ${ }^{\mathrm{c}}$ infraclavicular, ${ }^{\mathrm{f}}$ interpectoral, ${ }^{\mathrm{i}}$ close to side of recurrence. NA: not assessed. ${ }^{\mathrm{a}}$ means any SN outside ipsilateral axilla, patients had drainage to more than one basin (sometimes difficult to distinct number of nodes and number of patients). ${ }^{\mathrm{d}} 115$ patients: 2 had bilateral breast carcinoma. ${ }^{\mathrm{g}} 1$ patient had a previous axillary benign tissue resection and three melanoma surgery. ${ }^{\mathrm{h}} 10$ patients received radiotherapy to breast and axilla and 12 patients had breast surgery only. ${ }^{\mathrm{j}} 1$ patient had bilateral breast cancer, 5 patients had breast surgery only. ${ }^{\mathrm{k}}$ out of a series of 115 patients including previous breast surgery for benign pathology, overall 12 patients out of 115 had positive SN. 3 patients had a lumpectomy only and 3 were excluded because no blue dye was used. Internal mammary SN were not.

sidered as quality control surrogate marker in ALND. The median number of analysed lymph nodes was 13 (range 1 - 51) in a large retrospective study on 31,679 breast cancer patients [30]. There are important differences in ALND in breast cancer or in melanoma. So a complete lymph node dissection has the not the same magnitude in breast cancer (usually limited to level I and II) when compared to melanoma (usually including level I to III). This may partly explain the possibility to perform SLNB after previous "radical axillary dissection" in breast cancer patients. In melanoma patients ALND is regarded as a therapeutic procedure and as such it results in harvesting more lymph nodes than in breast cancer patients [31,32]. Redo ALND following previous ALND for breast cancer should be performed if necessary, because it may yield a similar or even a higher number of nodes compared with previous initial ALND [18].

\section{Comprehensive Anatomy of Lymphatics of the Upper Limb Trunk and Axilla}

Comprehensive reviews of upper limb and upper torso and breast lymphatic anatomies showed that lymphatics converge to a dominant axillary lymph node with numerous connexions to defined territories along the limb [33-35]. Some studies have observed that in SLNB for breast cancer, dermal and parenchymal lymphatics drain to the very same axillary node(s) [36], but lymphatic watershed in the breast does exist, thus explaining physiologic extra-axillary drainage. Based on Suami's study, peritumoral dye/radiocolloid injection should be preferred [37]. There is often more than one first-tier node [37]. Lymphatic drainage of the upper limb may rarely 
bypass level I and II of the axilla by using the way through lymphatics along cephalic vein and may drain directly in level III (infraclavicular fossa) [38]. This was already described in Sappey's drawings [33]. There are some connexions between superficial and deep lymphatic network [33], these may also account for interval sentinel nodes [38]. Of note, opening of lymphatic connections between deep and superficial network may prevent lymphedema after complete axillary dissection [39]. Variation in lymphatic vessels anatomy was illustrated by Wall et al. in patients with SLNB for trunk and extremities melanoma: this group showed that $30.5 \%$ of patients had multiple lymphatic channels draining to a single basin, while $58.8 \%$ had one single lymph channel only identified from the primary tumour site [40].

\section{To What Extent Previous Surgery and Lymphatic Dissection (SLNB or ALND) in the Axilla Would Change the Lymphatic Network and the Success for Second SLNB?}

Luini et al. showed that a previous breast biopsy would not modify SLNB accuracy in a study with 543 breast cancer patients and a 99\% SN identification rate [41]. In 70 breast cancer patients with previous breast augmentation or reduction surgery, SNs were identified in all and were positive in $32 \%$. Only one patient had bilateral axillary drainage and ipsilateral internal mammary drainage [42]. In another study, axillary SNs were seen in the axilla in $100 \%$ of patients following plastic surgery and in $91 \%$ after excisional biopsy only [25].

Table 1 shows that mean success rate for second SLNB was $70 \%(45 \%-100 \%)$ and was clearly related to previous axilla surgery in the larger series where subgroups were analysed: 38\% after ALND and 74\% after SLNB in Port's study [9], 50\% and 72\% respectively in van der Ploeg's study [25]. Schrenk et al. observed a $63 \%$ successful SN detection rate, which correlated with a positive lymphoscintigraphy and less than 10 nodes removed during the first axillary surgery [20]. Axelsson et al. observed however that success for second SLNB was not related to the number of lymph nodes at first surgery [22].

Compared to radical lymph node dissection, SLNB shows significantly a lower risk for lymphedema: in 4.6\% - 16\% for ALND patients and 0.3\% - 5\% for SLNB patients [43-45]. Lymphedema definition and measurement may vary, but there is a significantly increased risk with higher body weight, infection and injury after surgery [45]. Despite removal of a central key node or nearly all nodes, existing complex lymphatic network, accessory lymph channels or regenerated lymphatics may explain the fact that many patients did not experience lymphedema following a first axillary dissection [39] Lymphedema risk following second axillary dissection is unfortunately not reported in the reviewed papers in Table 1.

Fibrosis has been proven in an animal model as a key inhibitor in lymphatic regeneration. Extent of surgery or regional morbidity (lymphocele infection or lymphangitis) may explain why lymphatic anatomy is altered to various degrees [46]. Moreover, radiation and chemotherapy may also play a negative role in SN detection. Axillary dissection followed or not by radiotherapy may alter lymphatic drainage so that anterior chest may drain directly to internal mammary nodes $[47,48]$. Xing's meta-analysis showed that SLNB was still reliable following induction chemotherapy alone in breast cancer patients [49]. Some authors have observed that neither adjuvant radiotherapy $[9,17,21]$ nor chemotherapy [9] affect SN identification rate. Failures may also be explained by alteration of radiotracer detection by a change in lymphatic network (diffuse small lymphatics) due to fibrosis or because of an enlarged metastatic lymph node. One study observed blue dye failure in 9/11 patients [12] and another observed that only 50\% SNs were blue while $89 \%$ were hot [9], thus justifying the use of both tracer methods.

One interesting fact in table 1 is the proportion of $31 \%$ of extra-axillary SNs (15\% - 100\%) observed during second SLNB. This figure is in accordance with $6 \%-33 \%$ reported in the literature for first SLNB [9,25,27]. Extraaxillary SNs were more frequently observed after ALND (60\% - 84\%) than after SLNB (14\% - 65\%) at first surgery $[9,20,25]$. These were mainly IM and contralateral axilla, many times following ALND at first surgery. Surgery for extra-axillary SN is more demanding due to the need for internal mammary nodes and scary tissues dissection for example $[9,20,50]$.

In case of successful second SLNB, reliability of second SLNB was demonstrated either by 1) follow-up with negative axillary/extra-axillary recurrence, 2 ) by axillary dissection in patients with non-metastatic $\mathrm{SN}$ at second SLNB or 3) in patients where second SLNB failed. With a median follow-up of 45.9 months, Intra et al. did not observe any axilla recurrence in the 57 patients who had no further ALND after negative SLND [17]. Dinan et al. [12] had one single patient with SLNB at first surgery and negative SLNB at second surgery: a further ALND showed 14 negative nodes. In Schrenk's study, 13 patients out of 15 who had negative SN had a further ALND, which showed no other metastasis in a mean of 14.3 nodes (5 - 24), with a false negative rate of $0 \%$ [20]. Karam et al. chose to perform complementary ALND in 11 patients with successful second SLNB only in 4 patients who had SLNB at first surgery: none had positive 
nodes [23]. Port et al. removed additional non-SN in 23 out of 54 patients with successful reoperation with negative SN: one patient had positive internal mammary SN and the other a palpable positive non-SN [9]. Overall sensitivity and false negative rates were difficult to assess based because of incomplete data from table 1 .

Concomitant/sequential melanoma and breast cancer is indeed a rare event but was already described by Sood in 2004 (1 patient out of 4) [11] and by Schrenk in 2008 (3 out of 30) [20]. Collision tumours (SN with two histologically different metastatic deposits) with breast cancer and melanoma had a $0.5 \%$ incidence (52 cases in 20 years) at The Moffitt Cancer Centre [51]. Simultaneous neoplasms with only one of them detected can expose either to collision tumour or destruction of lymphatic pathways leading to a second metastatic undetected SN. In case of breast cancer a median delay of 20 months [29] would be necessary and only weeks for melanoma in order to observe a clinically or radiologically enlarged lymph node.

\section{What Should Be the Next Step for Patients Who Failed Second SLNB Detection?}

According to previous detection (SLNB or ALND) some authors propose surveillance [23]. Intra et al. detected positive nodes in one single such patient with a PET-CT [17], majority of authors propose in selected patients an ALND, who revealed positive nodes in $1 / 11$ patients [19], $1 / 2$ patients (out of 11 failures) [21], 2/3 patients (out of 7 failures) [23]. In the study of Port et al., 53 patients with failed second SLNB 29 had no further additional nodes and one patient out of 24 ALND (1-26 further nodes) had a metastatic lymph node [9]. Secondary ALND after a previous ALND is able to remove 0 - 16 further lymph nodes $[12,16,18,20]$.

\section{Conclusions}

Based on this comprehensive literature review, definitive conclusions are difficult to draw because of the rare condition, and because of the retrospective nature of the studies, the lack of complete survival data and data heterogeneity. Patients with a second malignancy are also usually excluded from randomized trials. However, following conclusions can be proposed:

1) Previous axillary dissection (SLNB or level I-II lymph node dissection for breast cancer) does not preclude a new SLNB (feasible in 70\%) and completion of ALND when positive SNs are detected. Even in more radical surgery for melanoma patients, SLNB would be able to detect where the actual lymphatic flow has been moved.

2) Due to multiplicity of unusual drainage way, classical triple technique of lymphatic mapping should be recommended, associating lymphoscintigraphy (dyna$\mathrm{mic} / \mathrm{static}$ ), blue dye injection and intraoperative use of hand held gamma probe. Of note, SLNB rules must be respected: remove all enlarged suspicious non SN.

3) In this setting when detected, extra-axillary SNs should be dissected as they may be the only $\mathrm{SN}$ and the only metastatic SN. Internal mammary SLNB is a standardized procedure $[27,31,47,50]$. It is however impossible to say if ALND can be avoided when only an extraaxillary SN is positive, in the same way as in a first SLNB [50].

4) In case of successful second axillary SLNB with negative SN and in case of extra-axillary SLNB with negative $\mathrm{SN}$, the absence of recurrence in the present review indicates that avoidance of complementary ALND is a safe option.

5) Complementary ALND should be discussed in case of failed second SLND. At least a strict follow-up combined with echography, CT-scan or PET-CT should be recommended.

6) Complementary ALND should be discussed when SLNB is positive (regardless of previous ALND or SLNB) and in contralateral axilla in case of positive contralateral positive SN.

\section{REFERENCES}

[1] J. Ferlay, P. Autier, M. Boniol, M. Heanue, M. Colombet and P. Boyle, "Estimates of the Cancer Incidence and Mortality in Europe in 2006," Annals of Oncology, Vol. 18, No. 3, 2007, pp. 581-592.

http://dx.doi.org/10.1093/annonc/mdl498

[2] V. Panet-Raymond, P. T. Truong, R. E. McDonald, C. Alexander, L. Ross, A. Ryhorchuk and P. H. Watson, "True Recurrence versus New Primary: An Analysis of Ipsilateral Breast Tumor Recurrences after Breast-Conserving Therapy," International Journal of Radiation Oncology, Biology, Physics, Vol. 81, No. 2, 2011, pp. 409-417. http://dx.doi.org/10.1016/j.ijrobp.2010.05.063

[3] J. L. Bulliard, R. G. Panizzon and F. Levi, "Epidémiologie et Prévention du Mélanome Cutané en Suisse,” Forum of Medical Suisse, Vol. 9, 2009, pp. 314-318.

[4] J. L. Bulliard, D. De Weck, T. Fisch, A. Bordoni and F. Levi, "Detailed Site Distribution of Melanoma and Sunlight Exposure: Aetiological Patterns from a Swiss Series,” Annals of Oncology, Vol. 18, No. 4, 2007, pp. 789794. http://dx.doi.org/10.1093/annonc/mdl490

[5] F. Levi, L. Randimbison, V. C. Te, M. M. Conconi and C. La Vecchia, "Risk of Prostate, Breast and Colorectal Cancer after Skin Cancer Diagnosis,” International Journal of Cancer, Vol. 123, No. 12, 2008, pp. 2899-2901. http://dx.doi.org/10.1002/ijc.23816

[6] P. T. Bradford, D. M. Freedman, A. M. Goldstein and M. A. Tucker, "Increased Risk of Second Primary Cancers after a Diagnosis of Melanoma," Archives of Dermatol- 
ogy, Vol. 146, No. 3, 2010, pp. 265-272. http://dx.doi.org/10.1001/archdermatol.2010.2

[7] S. Satram-Hoang, A. Ziogas and H. Anton-Culver, "Risk of Second Primary Cancer in Men with Breast Cancer," Breast Cancer Research, Vol. 9, No. 1, 2007, p. R10. http://dx.doi.org/10.1186/bcr1643

[8] M. R. Bower, C. R. Scoggins, R. C. Martin 2nd, M. P. Mays, M. J. Edwards, D. S. Reintgen, M. I. Ross, M. M. Urist, R. D. Noyes, J. J. Sussman, L. J. Hagendoorn, A. J. Stromberg and K. McMasters, "Second Primary Melanomas: Incidence and Outcome," The American Journal of Surgery, Vol. 76, No. 7, 2010, pp. 675-681.

[9] E. R. Port, C. A. Garcia-Etienne, J. Park, J. Fey, P. I. Borgen and H. S. Cody 3rd, "Reoperative Sentinel Lymph Node Biopsy: A New Frontier in the Management of Ipsilateral Breast Tumor Recurrence," Annals of Surgical Oncology, Vol. 14, No. 8, 2007, pp. 2209-2214. http://dx.doi.org/10.1245/s10434-006-9237-z

[10] G. Palit, Y. Jacquemyn and W. Tjalma, "Sentinel Node Biopsy for Ipsilateral Breast Cancer Recurrence: A Review," European Journal of Gynaecological Oncology, Vol. 29, No. 6, 2008, pp. 565-567.

[11] A. Sood, I. M. Youssef, S. I. Heiba, H. El-Zeftawy, D. Axelrod, B. Seigel, C. Mills and H. M. Abdel-Dayem, “Alternative Lymphatic Pathway after Previous Axillary Node Dissection in Recurrent/prImary Breast Cancer," Clinical Nuclear Medicine, Vol. 29, No. 11, 2004, pp. 698-702.

http://dx.doi.org/10.1097/00003072-200411000-00005

[12] D. Dinan, C. E. Nagle and J. Pettinga, "Lymphatic Mapping and Sentinel Node Biopsy in Women with an Ipsilateral Second Breast Carcinoma and a History of Breast and Axillary Surgery,” The American Journal of Surgery, Vol. 190, No. 4, 2005, pp. 614-617. http://dx.doi.org/10.1016/j.amjsurg.2005.06.025

[13] A Agarwal, DE Heron, J Sumkin, J Falk, “Contralateral uptake and metastases in sentinel lymph node mapping for recurrent breast cancer," Journal of Surgical Oncology, Vol. 92, No. 1, 2005, pp. 4-8. http://dx.doi.org/10.1002/jso.20282

[14] E. A. Newman, V. M. Cimmino, M. S. Sabel, K. M. Diehl, K. A. Frey, A. E. Chang and L. A. Newman, "Lymphatic Mapping and Sentinel Lymph Node Biopsy for Patients with Local Recurrence after Breast-Conservation Therapy,” Annals of Surgical Oncology, Vol. 13, No. 1, 2006, pp. 52-57. http://dx.doi.org/10.1245/ASO.2006.12.002

[15] R. M. H. Roumen, G. P. Kuijt and I. H. Liem, "Lymphatic Mapping and Sentinel Node Harvesting in Patients with Recurrent Breast Cancer,” European Journal of Surgical Oncology, Vol. 32, No. 10, 2006, pp. 1076-1081. http://dx.doi.org/10.1016/j.ejso.2006.08.007

[16] B. Taback, P. Nguyen, N. Hansen, G. K. Edwards, K. Conway and A. E. Giuliano, "Sentinel Lymph Node Biopsy for Local Recurrence of Breast Cancer after BreastConserving Therapy," Annals of Surgical Oncology, Vol. 13, No. 8, 2006, pp. 1099-1104. http://dx.doi.org/10.1245/ASO.2006.08.026

[17] M. Intra, G. Trifirò, V. Galimberti, O. Gentilini, N. Rot- mensz and P. Veronesi, "Second Axillary Sentinel Node Biopsy for Ipsilateral Breast Tumour Recurrence,” British Journal of Surgery, Vol. 94, No. 10, 2007, pp. 1216-1219. http://dx.doi.org/10.1002/bjs.5813

[18] J. L. Barone, S. M. Feldman, A. Estabrook, P. I. Tartter, S. M. Rosenbaum Smith and S. K. Boolbol, ”Reoperative Sentinel Lymph Node Biopsy in Patients with Locally Recurrent Breast Cancer," The American Journal of Surgery, Vol. 194, No. 4, 2007, pp. 491-493. http://dx.doi.org/10.1016/j.amjsurg.2007.07.011

[19] M. Koizumi, M. Koyama, K. Tada, S. Nishimura, Y. Miyagi, M. Makita, M. Yoshimoto, T. Iwase, R. Horii, F. Akiyama and T. Saga, "The Feasibility of Sentinel Node Biopsy in the Previously Treated Breast," European Journal of Surgical Oncology, Vol. 34, No. 4, 2008, pp. 365368. http://dx.doi.org/10.1016/j.ejso.2007.04.007

[20] P. Schrenk, C. Tausch and W. Wayand, "Lymphatic Mapping in Patients with Primary or Recurrent Breast Cancer Following Previous Axillary Surgery,” European Journal of Surgical Oncology, Vol. 34, No. 8, 2008, pp. 851-856. http://dx.doi.org/10.1016/j.ejso.2007.11.006

[21] C. E. Cox, B. T. Furman, J. V. Kiluk, J. Jara, W. Koeppel, T. Meade, L. White, E. Dupont, N. Allred and M. Meyers, "Use of Reoperative Sentinel Lymph Node Biopsy in Breast Cancer Patients,” Journal of the American College of Surgeons, Vol. 207, No. 1, 2008, pp. 57-61. http://dx.doi.org/10.1016/j.jamcollsurg.2008.01.017

[22] C. K. Axelsson and P. E. Jønsson, “Sentinel Lymph Node Biopsy in Operations for Recurrent Breast Cancer," European Journal of Surgical Oncology, Vol. 34, No. 6, 2008, pp. 626-630. http://dx.doi.org/10.1016/j.ejso.2007.09.004

[23] A. Karam, M. Stempel, H. S. Cody III, E. R. Port, "Reoperative Sentinel Lymph Node Biopsy after Previous Mastectomy," Journal of the American College of Surgeons, Vol. 207, No. 4, 2008, pp. 543-548. http://dx.doi.org/10.1016/j.jamcollsurg.2008.06.139

[24] R. Tasevski, A. J. Gogos and G. B. Mann, "Reoperative Sentinel Lymph Node Biopsy in Ipsilateral Breast Cancer Relapse,” Breast, Vol. 18, No. 5, 2009, pp. 322-326. http://dx.doi.org/10.1016/j.breast.2009.09.009

[25] I. M. C. Van der Ploeg, H. S. Oldenburg, E. J. T. Rutgers, M. J. Baas-Vrancken Peeters, B. B. Kroon, R. A. Valdes Olmos and O. E. Nieweg, "Lymphatic Drainage Patterns from the Treated Breast," Annals of Surgical Oncology, Vol. 17, No. 4, 2010, pp. 1069-1075. http://dx.doi.org/10.1245/s10434-009-0841-6

[26] F. Derkx, A. J. G. Maaskant-Braat, M. J. C. van der Sangen, G. A. Nieuwenhuijzen, L. V. van de Poll-Franse, R. M. Roumen and A. C. Voogd, "Staging and Management of Axillary Lymph Nodes in Patients with Local Recurrence in the Breast or Chest Wall after a Previous Negative Sentinel Node Procedure," European Journal of Surgical Oncology, Vol. 36, No. 7, 2010, pp. 646-651. http://dx.doi.org/10.1016/j.ejso.2010.05.009

[27] H. S. Cody 3rd, "Clinical Significance and Management of Extra-Axillary Sentinel Lymph Nodes: Worthwhile or Irrelevant?" Surgical Oncology Clinics of North America, Vol. 19, No. 3, 2010, pp. 507-517. 


\section{http://dx.doi.org/10.1016/j.soc.2010.04.002}

[28] M. G. Statius Muller, F. A. Hennipman, P. A. van Leeuwen, R. Pijpers, R. J. Vuylsteke and S. Meijer, "Unpredictability of Lymphatic Drainage Patterns in Melanoma Patients," European Journal of Nuclear Medicine, Vol. 29, No. 2, 2002, pp. 255-261. http://dx.doi.org/10.1007/s00259-001-0670-8

[29] I. M. C. Van der Ploeg, O. E. Nieweg, M. C. van Rijk, R. A. Valdes Olmos and B. B. Kroon, “Axillary Recurrence after a Tumour-Negative Sentinel Node Biopsy in Breast Cancer Patients: A Systematic Review and Meta-Analysis of the Literature," European Journal of Surgical Oncology, Vol. 34, No. 12, 2008, pp. 1277-1284. http://dx.doi.org/10.1016/j.ejso.2008.01.034

[30] C. K. Axelsson, H. T. Mouridsen, M. During and S. Moller, "Axillary Staging during Surgery for Breast Cancer," British Journal of Surgery, Vol. 94, No. 3, 2007, pp. 304309. http://dx.doi.org/10.1002/bjs.5599

[31] C. D. Haagensen, "Lympahtics of the Breast,” In: C. D. Haagensen, C. R. Feind and F. P. Herter, Eds., The Lymphatics in Cancer, WB Saunders, Philadelphia, 1972, pp. 300-398.

[32] J. A. Petrek and M. M. Blackwood, “Axillary Dissection: Current Practice and Technique," Current Problems in Surgery, Vol. 32, No. 4, 1995, pp. 258-323. http://dx.doi.org/10.1016/S0011-3840(05)80015-2

[33] H. Suami, G. I. Taylor and W. R. Pan, "The Lymphatic Territories of the Upper Limb: Anatomical Study and Clinical Implications,” Plastic and Reconstructive Surgery, Vol. 119, No. 6, 2007, pp. 1813-1822. http://dx.doi.org/10.1097/01.prs.0000246516.64780.61

[34] H. Suami, J. K. O’Neill, W. R. Pan and G. I. Taylor, "Superficial Lymphatic System of the Upper Torso: Preliminary Radiographic Results in Human Cadavers," Plastic and Reconstructive Surgery, Vol. 12, No. 4, 2008, pp. 1231-1239. http://dx.doi.org/10.1097/01.prs.0000302511.21140.36

[35] N. Browse, K. G. Burnand and P. S. Mortimer, "Chapter 2. Anatomy,” In: N. Browse, K. G. Burnand and P. S. Mortimer, Eds., Disease of the Lymphatics, Arnold, London, 2003, pp. 21-43.

[36] S. D. Nathanson, D. L. Wachna, D. Gilman, K. Karvelis, S. Havstad and J. Ferrara, "Pathways of Lymphatic Drainage form the Breast,” Annals of Surgical Oncology, Vol. 8, No. 10, 2001, pp. 837-843. http://dx.doi.org/10.1007/s10434-001-0837-3

[37] H. Suami, W. R. Pan, G. B. Mann and G. I. Taylor, "The lymphatic Anatomy of the Breast and Its Implications for Sentinel Lymph Node Biopsy: A Human Cadaver Study,” Annals of Surgical Oncology, Vol. 15, No. 3, 2008, pp. 863-871. http://dx.doi.org/10.1245/s10434-007-9709-9

[38] M. Matter, M. N. Lalonde, M. Allaoua, A. Boubaker, D. Lienard, O. Gugerli, J. P. Cerottini, H. Bouzourene, A. B. Delaloye and F. Lejeune, "The Role of Interval Nodes in Sentinel Lymph Node Mapping and Dissection for Melanoma Patients,” Journal of Nuclear Medicine, Vol. 48, No. 10, 2007, pp. 1607-1613.

http://dx.doi.org/10.2967/jnumed.107.041707
[39] H. Suami, W. R. Pan and G. I. Taylor, "Changes in the Lymph Structure of the Upper Limb after Axillary Dissection: Radiographic and Anatomical Study in a Human Cadaver,” Plastic \& Reconstructive Surgery, Vol. 120, No. 4, 2007, pp. 982-991. http://dx.doi.org/10.1097/01.prs.0000277995.25009.3e

[40] J. K. Wall, M. Florero, N. A. Accortt, R. Allen, M. Kashani-Sabet, E. Morita and S. P. Leong, "Impact of Multiple Lymphatic Channel Drainage to a Single Nodal Basin on Outcomes in Melanoma,” JAMA Surgery, Vol. 142, No. 8, 2007, pp. 753-758. http://dx.doi.org/10.1001/archsurg.142.8.753

[41] A. Luini, V. Galimberti, G. Gatti, P. Arnone, A. R. Vento, G. Trifiro, G. Viale, N. Rotmensz, J. R. Fernandez, D. Gilardi and G. Paganelli, “The Sentinel Node Biopsy after Previous Breast Surgery: Preliminary Results on $543 \mathrm{~Pa}$ tients Treated at the European Institute of Oncology," Breast Cancer Research and Treatment, Vol. 89, No. 2, 2005, pp. 159-163. http://dx.doi.org/10.1007/s10549-004-1719-8

[42] J. R. Fernandez, S. Martella, G. Trifirò, M. Caliskan, C. Chifu, F. Brenelli, E. Botteri, F. Rossetto, N. Rotmensz, M. Rietjens and P. Veronesi, "Sentinel Node Biopsy in Patients with Previous Breast Aesthetic Surgery,” Annals of Surgical Oncology, Vol. 16, No. 4, 2009, pp. 989-992. http://dx.doi.org/10.1245/s10434-009-0349-0

[43] W. R. Wrightson, S. L. Wong, M. J. Edwards, C. Chao, D. S. Reintgen, M. I. Ross, R. D. Noyes, V. Viar, P. B. Cerrito, K. M. McMasters, Sunbelt Melanoma Trial Study Group, "Complications Associated with Sentinel Lymph Node Biopsy for Melanoma,” Annals of Surgical Oncology, Vol. 10, No. 6, 2003, pp. 676-680. http://dx.doi.org/10.1245/ASO.2003.10.001

[44] R. Crane-Okada, R. A. Wascher, D. Elashoff and A. E. Giulano, “Long-Term Morbidity of Sentinel Node Biopsy Versus Complete Axillary Dissection for Unilateral Breast Cancer," Annals of Surgical Oncology, Vol. 15, No. 7, 2008, pp. 1996-2005. http://dx.doi.org/10.1245/s10434-008-9909-y

[45] S. A. McLaughlin, M. J. Wright, K. T. Morris, G. L. Giron, M. R. Sampson, J. P. Brockway, K. E. Hurley, E. R. Riedel and K. J. Van Zee, "Prevalence of Lymphedema in Women with Breast Cancer 5 Years after Sentinel Lymph Node Biopsy or Axillary Dissection: Objective Measurements,” Journal of Clinical Oncology, Vol. 26, No. 32, 2008, pp. 5213-5219. http://dx.doi.org/10.1200/JCO.2008.16.3725

[46] T. Avraham, N. W. Clavin, S. V. Daluvoy, J. Fernandez, M. A. Soares, A. P. Cordeiro and B. J. Mehrara, "Fibrosis Is a Key Inhibitor of Lymphatic Regeneration,” Plastic \& Reconstructive Surgery, Vol. 124, No. 2, 2009, pp. 438450. http://dx.doi.org/10.1097/PRS.0b013e3181adcf4b

[47] J. F. Thompson, R. F. Uren, R. P. M. Saw and G. N. Stevens, "Internal Mammary Node Metastasis from Primary Cutaneous Melanoma on the Anterior Chest," ANZ Journal of Surgery, Vol. 75, No. 8, 2005, pp. 723-725. http://dx.doi.org/10.1111/j.1445-2197.2005.03494.x

[48] S. M. Ansari, S. I. Heiba, C. Mills and H. M. AbdelDayem, "Localization of the Breast Sentinel Node after 
Axillary Node Dissection with Diversion of Lymphatic Drainage to Internal Mammary Lymph Nodes and the Importance of Delayed Imaging," Clinical Nuclear Medicine, Vol. 26, No. 7, 2001, pp. 647-648. http://dx.doi.org/10.1097/00003072-200107000-00023

[49] Y. Xing, M. Foy, D. D. Cox, H. M. Kuerer, K. K. Hunt and J. N. Cormier, "Meta-Analysis of Sentinel Lymph Node Biopsy after Preoperative Chemotherapy in Patients with Breast Cancer," British Journal of Surgery, Vol. 93, No. 5, 2006, pp. 539-546. http://dx.doi.org/10.1002/bjs.5209

[50] I. M. C. Van der Ploeg, P. J. Tanis, R. A. Valdés Olmos, B. B. Kroon, E. J. Rutgers and O. E. Nieweg, "Breast
Cancer Patients with Extra-Axillary Sentinel Nodes Only may be Spared Axillary Lymph Node Dissection,” Annals of Surgical Oncology, Vol. 15, No. 11, 2008, pp. 32393243. http://dx.doi.org/10.1245/s10434-008-0120-y

[51] J. M. Farma, J. S. Zager, V. Barnica-Elvir, C. A. Puleo, S. S. Marzban, D. E. Rollison, J. L. Messina and V. K. Sondak, "A Collision of Diseases: Chronic Lymphocytic Leukemia Discovered During Lymph Node Biopsy for Melanoma,” Annals of Surgical Oncology, Vol. 20, No. 4, 2013, pp. 1360-1364.

http://dx.doi.org/10.1245/s10434-012-2740-5

\section{Abbreviations}

SN: sentinel lymph node;

SLNB: sentinel lymph node biopsy;

ALND: axillary radical lymph node dissection. 